\title{
Synthesis And Characterization Of Nano Structured (4- Aminopyridine) Copper (Ii) Acetate Chloride
}

\author{
${ }^{1}$ A. Sinthiya, ${ }^{2,}$ Babu Varghese \\ ${ }^{1}$ Department of Physics, St. Joseph's College (Autonomous), Tiruchirappalli - 620 002, INDIA \\ ${ }^{2}$ Sophisticated Analytical Instruments Facility, Indian Institute of Technology Madras \\ Chennai 600 036, TamilNadu, India.
}

\begin{abstract}
The greenish blue $\left[\mathrm{C}_{5} \mathrm{H}_{6} \mathrm{~N}_{2}\right] \mathrm{Cu}_{4}\left[\mathrm{C}_{4} \mathrm{H}_{6} \mathrm{O}_{4}\right] \mathrm{Cl}_{2}$ particles have been prepared at the room temperature. The grown particles were observed using high-resolution transmission electron microscopy-HRTEM. The results show that, the as-grown particles have the nano tube like structure with breadth $70.9 \mathrm{~nm}$ size, and have the structure of 4-aminopyridine copper II acetate chloride. Using Scherrer equation the calculated crystallite size is $0.0325 \mathrm{~nm}$ for $K=1$ and crystallite size is $0.0293 \mathrm{~nm}$ for $K=0.9$. Using Williamson and Hall theories the calculated $\Delta K\left(\mathrm{~nm}^{-1}\right)$ from FWHM is tabulated. From scatter plot we could identify that the more points strongly tend to cluster around a straight line, and it ensures that there is a linear relationship between the two variables (the higher the correlation). Moreover the line around which the points tends to cluster runs from lower left to upper right, so the relationship between the two variable is positive (direct).The elemental analysis conforms that it has $28.01 \%$ of carbon, $2.73 \%$ of hydrogen, $7.01 \%$ of nitrogen, $21.45 \%$ of oxygen, $18.64 \%$ of copper and $19.08 \%$ of chloride. The calculated molecular mass of the as - grown nano tube like structured particle is $346.65 \mathrm{~g} / \mathrm{mol}$
\end{abstract}

Key Words: Fampyridine, acetate, copper chloride, nano tube, HRTEM,Scherrer formula, Williamson and Hall plot

\section{Introduction}

The first metal-base caged compound capable of releasing organic biomolecules was [Ru(bpy)2(4AP)2]2+, where 4AP is 4 aminopyridine, a $\mathrm{K}^{+}$(potassium ) channel blocker[1]. Only a few caged neurochemicals have been prepared so far using the metal coordination strategy, the technique has a promising future. A caged compound must contain an interior cavity in which one or more molecules in ions can be trapped. Metal - assembled cages consists of multi-denate ligands held together by metal cations [2] which are unique because their bonds are more easily broken allowing the movement of guest molecules through the cavity [3]. These cages have potential applications in the area of molecular recognition, light harvesting, bio molecular transport and delivery systems, waste clean-up and time-released medicine [4].Fampyridine, a new sustained release oral tablet of 4-AP is currently under phase III clinic trial for its therapeutic efficacy in patients with multiple sclerosis (MS) and chronic spinal cord injury. Low concentration of 4-AP are considered to block transient, voltage activated, outward $\mathrm{K}^{+}$currents [5].Potassium ions $\left(\mathrm{K}^{+}\right)$and sodium ions $\left(\mathrm{Na}^{+}\right)$flow between the neurons and the extracellular fluid to set up the state of electrical charge potential when the neuron is at rest (the resting potential) and to release that potential when the neuron is sending a nerve impulse (the action potential). Sodium ions flow through other special gates called "sodium channels". . Voltage - gated channels open or close in response to the surrounding electro - potential while chemically gated ones open and close in response to chemical stimuli. Dendrites, the branched filaments that receive nerve transmissions from other neurons, tend to have more chemically - gated potassium channels and fewer voltage - gated potassium channels by comparison with axons, the long extensions that send these transmissions onto other neurons.Clinically for Lambert - Eaton myasthenic syndrome 4aminopyridine is used because it is blocking potassium channels. It prolongs action potentials thereby increasing transmitter release at the neuromuscular junctions $[6,7,8,9]$. The structure of 4- aminopyridine $\mathrm{C}_{5} \mathrm{H}_{6} \mathrm{~N}_{2}$ has been redetermined at $150 \mathrm{~K}$ [10]. Also for the same compound, the structure has been reported at room temperature [11]. Though this compound was not analysed and reported for its physical properties from our literature survey, the synthesis and characterization of crystals as well as other nano structured behaviour have been reported in this paper based on their potential applications in biomedical and industrial need. This paper was aimed at developing green approach based synthesis of nanomaterial viz. nano structured $\left[\mathrm{C}_{5} \mathrm{H}_{6} \mathrm{~N}_{2}\right] \mathrm{Cu}\left[\mathrm{C}_{4} \mathrm{H}_{6} \mathrm{O}_{4}\right] \mathrm{Cl}_{2}$. with the suitable green solvent . Also 
analysis was made with reference to its Powder XRD, spectroscopic characteristics (FTIR, UV and HRTEM) and composition of elements present in the material X-ray diffraction is a promising tool for structural analysis of solid or amorphous materials and approaches such as use of Sherrer equation, integral breadth analysis, single-line approximation, Hall-Williamson method, etc., have been developed for estimation of crystallite size. Numerous experiments have shown that the strain broadening caused by dislocations can be well described by a special logarithmic series expansion of the Fourier coefficients of Bragg reflection peak profiles. X-ray diffraction peak profile analysis is used for the characterization of microstructure either in the bulk or in loose powder materials, which is a nondestructive method yielding a series of interesting microstructural parameters[13].

\subsection{EXPERIMENTAL PROCEDURE}

\section{Methodology}

All the reagents used for the preparation of sample are analytical grade and the solutions are prepared using pure de-ionized distilled water. A solution of 4-aminopyridine $(0.3768 \mathrm{~g})$ in $99.9 \%$ pure distilled water $(20 \mathrm{ml})$ was added to a solution of $\mathrm{CuCl}_{2} \cdot 2 \mathrm{H}_{2} \mathrm{O}(1.7048 \mathrm{~g})$ in $99.9 \%$ pure distilled water and one drop of diluted acetic acid was added and mixture was prepared at $30^{\circ} \mathrm{C}$. Greenish blue solution was obtained and it was filtered and the filtrate was dried at the room temperature. The chemical reaction taking place in the growth process is:

$$
\begin{aligned}
& \mathrm{CuCl}_{2} \cdot 2 \mathrm{H}_{2} \mathrm{O}+4 \mathrm{C}_{5} \mathrm{H}_{6} \mathrm{~N}_{2} \\
& {\left[\mathrm{CuCl}_{2}\left(\mathrm{C}_{5} \mathrm{H}_{6} \mathrm{~N}_{2}\right)_{4}\right] \cdot \mathrm{H}_{2} \mathrm{O}+\mathrm{CH}_{3} \mathrm{COOH}}
\end{aligned} \rightarrow \begin{gathered}
{\left[\mathrm{CuCl}_{2}\left(\mathrm{C}_{5} \mathrm{H}_{6} \mathrm{~N}_{2}\right)_{4}\right] . \mathrm{H}_{2} \mathrm{O}+\mathrm{H}_{2} \mathrm{O} \uparrow} \\
{\left[\mathrm{C}_{5} \mathrm{H}_{6} \mathrm{~N}_{2}\right] \mathrm{Cu}\left[\mathrm{C}_{4} \mathrm{H}_{6} \mathrm{O}_{4}\right] \mathrm{Cl}_{2} .+\mathrm{H}_{2} \mathrm{O} \uparrow}
\end{gathered}
$$

The greenish blue $\left[\mathrm{C}_{5} \mathrm{H}_{6} \mathrm{~N}_{2}\right] \mathrm{Cu}\left[\mathrm{C}_{4} \mathrm{H}_{6} \mathrm{O}_{4}\right] \mathrm{Cl}_{2}$. nano tube like structured particles of the titled compound were obtained after 2 weeks.

The structure of Tetrakis (4-aminopyridine $-{ }_{\mathrm{k}} \mathrm{N}^{1}$ ) - dichlorocopper (II) monohydrate has been reported [12] in which the pyridine nitrogen is co-ordinated to copper (II) ${ }^{+}$ion along with the 2 chloride ions. This compound is treated with one drop of diluted acetic acid which resulted in the greenish blue nanostructured adduct of 4-aminopyridine copper II acetate chloride .

\subsection{Powder XRD pattern}

\section{Results And Discussion}

The powder sample subjected to X-ray diffractometer within $2 \theta$ range of 20-60 at a scan speed of $7^{\circ}$ per minute using a $\mathrm{Cu}$ target and $\mathrm{Cu}-\mathrm{K} \alpha$ radiation of $0.15406 \mathrm{~nm}$ wavelength at a powder rating of $40 \mathrm{kV}, 40 \mathrm{~mA}$ using Brukker D8 diffractometer. Figure 1 shows the powder XRD pattern and it has been indexed in Table 1.

\subsection{Crystallite size estimation}

According to the Scherrer equation [14], the broadening due to small crystallite size may be expressed as

$$
B_{C}=\mathrm{k} \lambda / \mathrm{t} \cos \theta .
$$

where $B_{C}$ is the broadening, solely due to small crystallite size, $\mathrm{k}$ a constant whose value depends on particle shape and usually taken as $1.0, \mathrm{t}$ the crystallite size in nanometers, $\theta$ the Bragg's angle and $\lambda$ the wave length of incident X-ray beam in $\mathrm{nm}$. It is found for the synthesized $\left[\mathrm{C}_{5} \mathrm{H}_{6} \mathrm{~N}_{2}\right] \mathrm{Cu}\left[\mathrm{C}_{4} \mathrm{H}_{6} \mathrm{O}_{4}\right] \mathrm{Cl}_{2} \cdot \mathrm{H}_{2} \mathrm{O}$ nanostructured material the calculated crystallite size is $0.0325 \mathrm{~nm}$ for $\mathrm{K}=1$ and crystallite size is $0.0293 \mathrm{~nm}$ for $\mathrm{K}=0.9$.

\subsection{Diffraction peak profiles}

Irrespective of diffraction order, for size broadening and dependence on strain broadening, Williamson and Hall suggested that the FWHM of diffraction peak profiles can be written as the sum of the two broadening effects [15]. Here $\mathrm{K}=2 \sin \theta / \lambda, \Delta \mathrm{K}=2 \cos \theta \Delta \theta / \lambda,(\theta, \Delta \theta$, and $\lambda$ are the diffraction angle, half of the FWHM of the diffraction peak and the wavelength of X-rays, respectively) and $g=K$ at the exact Bragg position. The calculated $\Delta \mathrm{K}\left(\mathrm{nm}^{-1}\right)$ from FWHM is tabulated in Table 2.

\subsection{Scatter matrix plot}

A scatter matrix is a pair-wise scatter plot of several variables presented in a matrix format. It can be used to determine whether the variables are correlated and whether the correlation is positive or negative[16]. The maximum likelihood estimate, given $n$ samples, for the covariance matrix of a multivariate normal distribution can be expressed as the normalized scatter matrix[17]. A scatter plot is a useful summary of a set of bivariate data (two variables), usually drawn before working out a linear correlation coefficient or fitting a 
regression line. It gives a good visual picture of the relationship between the two variables and aids the interpretation of the correlation coefficient or regression model. Each unit contributes one point to the scatter plot on which points are plotted but not joined. The resulting pattern indicates the type and strength of the relationship between the two variables[18].Following figure 2 shows the scatter plot between $\mathrm{I} / \mathrm{I}_{\max }(\%)$ and $\Delta \mathrm{K}\left(\mathrm{nm}^{-1}\right)$. From this plot we could identify that the more points strongly tend to cluster around a straight line, and it ensures that there is a linear relationship between the two variables (the higher the correlation). Moreover the line around which the points tends to cluster runs from lower left to upper right, so the relationship between the two variable is positive (direct).

\subsection{Elemental analysis}

C.H.N. analysis was carried out in the department of chemistry, IIT, Madras, using Perkin Elmer : series II CHNS/O elemental Analyser for $\left[\mathrm{C}_{5} \mathrm{H}_{6} \mathrm{~N}_{2}\right] \mathrm{Cu}\left[\mathrm{C}_{4} \mathrm{H}_{6} \mathrm{O}_{4}\right] \mathrm{Cl}_{2}$. Table 3 shows the composition of $\mathrm{CHN}$ in percentage and this table has the $\%$ of metal ion found out by titrimetric method and the $\%$ was consistent with theoretical values.

\subsection{HRTEM Images}

High-resolution transmission electron microscopy HRTEM values are recorded using JEOL 3010 with accelerating voltage $200 \mathrm{KV}$. Figure 3 shows the reciprocal lattice, which gives the two dimension information and it is SAD selected area diffraction pattern. We focused only on particular orientation, and we found that $\mathrm{CuCl}_{2}$ with hexagonal call parameters. The calculated value of $\mathrm{a}=0.79 \mathrm{~nm}=\mathrm{b}$. For the Hexagonal system $\mathrm{a}=\mathrm{b} \neq \mathrm{c}$. Since it is a two dimensional information we could get values for a and b only. Figure 4 shows the magnification at $20 \mathrm{~nm}$. At this magnification nano tube like structured ligand is formed with breadth $70.9 \mathrm{~nm}$. The presence of copper connected to the ligand is conformed by the Figure 5 for 50nm magnification. The nano tube structured ligand has well defined boundary and it is shown in figure 6 . At magnification $5 \mathrm{~nm}$, the $\mathrm{d}=1.93 \mathrm{~nm}$ and $\mathrm{d}=0.3 \mathrm{~nm}$ conforms that the grains are arranged periodically. Here physical crystal are developed in planes and it is shown in figure 7. Figure 8 shows the presence of acetate at $10 \mathrm{~nm}$ magnification. This acetate and copper chloride HRSEM structure well aggregates the structure reported by Umme Farva et al. Figure 9 conforms the periodicity with the $\mathrm{d}=0.32 \mathrm{~nm}$ and $\mathrm{d}=0.55 \mathrm{~nm}$ at $5 \mathrm{~nm}$ magnification. Figure 10 shows that at the another orientation for $5 \mathrm{~nm}$ magnification the interaction of particles conforms with different atomic distances and it is tabulated in the table with reference to the Jebas et al.,[12]. Figure 11 shows that as the electron beam voltage increases the particles get dispersed and spherical shaped particles are identified

\section{Conclusion}

The as-grown particles have the nano tube like structure with breadth $70.9 \mathrm{~nm}$ size, and have the structure of 4-aminopyridine copper II acetate chloride. Using Scherrer equation the calculated crystallite size is $0.0325 \mathrm{~nm}$ for $\mathrm{K}=1$ and crystallite size is $0.0293 \mathrm{~nm}$ for $\mathrm{K}=0.9$. Using Williamson and Hall theories the calculated $\Delta \mathrm{K}\left(\mathrm{nm}^{-1}\right)$ from FWHM is tabulated. From scatter plot we could identify that the more points strongly tend to cluster around a straight line, and it ensures that there is a linear relationship between the two variables (the higher the correlation). Moreover the line around which the points tends to cluster runs from lower left to upper right, so the relationship between the two variable is positive (direct). The elemental analysis conforms that it has $28.01 \%$ of carbon, $2.73 \%$ of hydrogen , $7.01 \%$ of nitrogen, $21.45 \%$ of oxygen, $18.64 \%$ of copper and $19.08 \%$ of chloride. The calculated molecular mass of the as -grown nano tube like structured particle is $346.65 \mathrm{~g} / \mathrm{mol}$

\section{Reference}

[1]. Zayat et al., 2003, A new strategy for neurochemical photodelivery, Metal-ligand heterolytic cleavage, J. Am. Chem. Soc., 125: 882-883.

[2]. Baxter, P.N.W., Sauvage, T.P., Hosseini, M.W., 1996, Comprehensive Supramolecular Chemistry, Metal Ion Directed Assembly of complex Molecular Architectures and Nanostructures, Pergamon, Oxford,, 165-211.

[3]. Amrehein, Wash, P.L., Shivanyuk, A., Rebek, 2002. J. Org. Letters,4: 319-32.

[4]. Ikeda, A., Udzu, H., Yashimura, M., Shinkai, S., 2000.Tetrahedron, 56:1825-1832.

[5]. Taccola, G. and Nistri,2005. A., Acta Neurochir, $93: 151-154$.

[6]. .P. Pohanish, Stanley A, 2009. Wiley guide to chemical incompatibilities, Greene, John Wiley and sons, second edition, P 64.

[7]. Jude S. and Bever C.,2006. Pharmacol.,111:224-259.

[8]. Strupp, M., Malla, R., Dichgan, M., Fraitinger, T., Glasaner, S. and Brandt, 2004. T., Neurology, 62: 1623-1625.

[9]. Schwid, S. B., Petrie, M. D., Mc Dermott, M.P, Tierney. D.S., Mason. D.H and Goodman A.D,1997. Neurology, 48: 817-821.

[10]. Andersonn et al., 2005. Actacryst, E61 : o1350-o1353.

[11]. Chao, M. and Schempp. E., 1977. Acta Cryst., B33:1557-1564. 
[12]. Sinthiya, A., Samuel Robinson Jebas and Suganthi Devadasan, 2008. Acta Cryst..E64 : m853-m854.

[13]. Michael B. Kerber et al., 2005. Rev.Adv.Mater.Sci., 10: 427-433.

[14]. Scherrer P, 1981. Math Phys K,, $1: 98$.

[15]. G.K. Williamson and W.H. Hall, 1953. Acta metal. 1: 22.

[16]. http://www.originlab.com/www/helponline/origine/en/userGuide/Scatter matrix Graph.html

[17]. http://en.wikipedia.org/wiki/scatter_matrix

[18]. http://www.stats.gla.ac.uk/steps/glossary/presenting data.html\#scat

[19]. Umme Farva et al., Optimization study of copper precursors for high quality $\mathrm{CuLnSe}_{2}$ nanoparticles by wet chemical route. 978-14244-5892-9/10/\$26.00@2010 IEEE, 003472-003473.

Figure 1: Powder XRD pattern

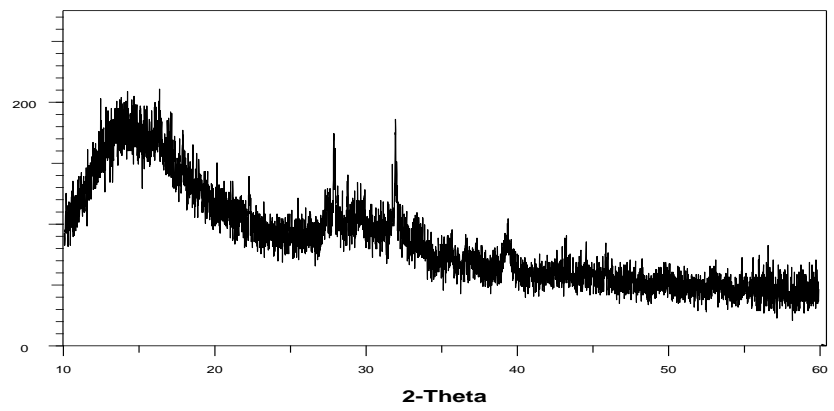

Figure 2 : Scatter plot

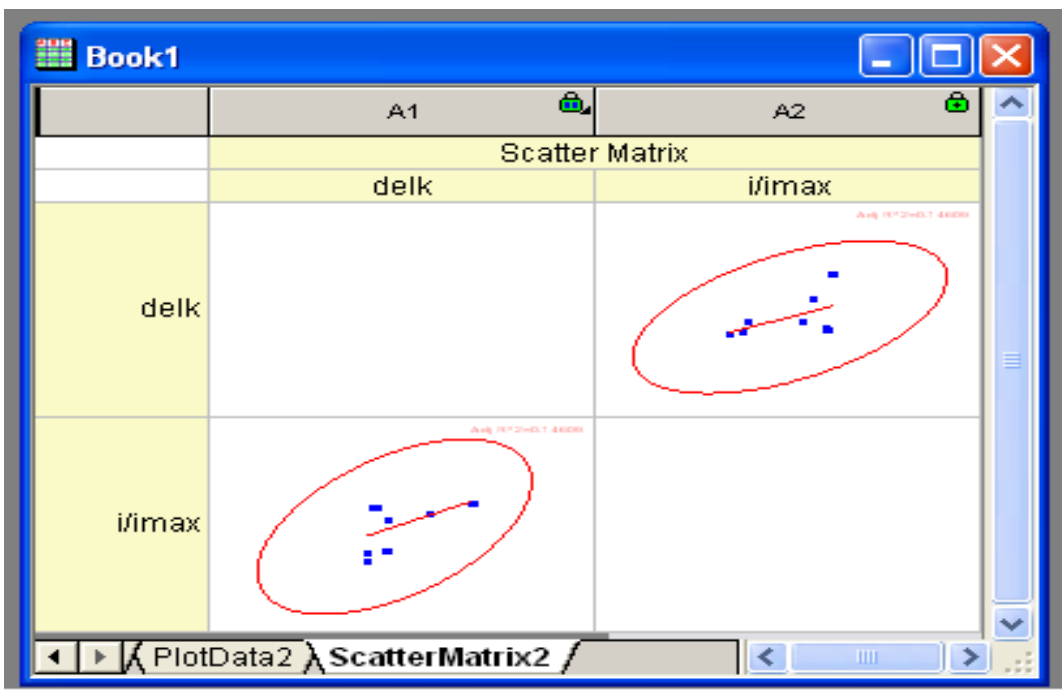

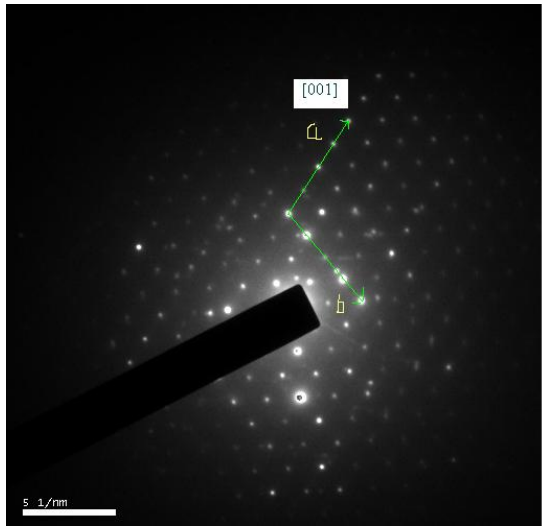

Figure 3: SAD pattern

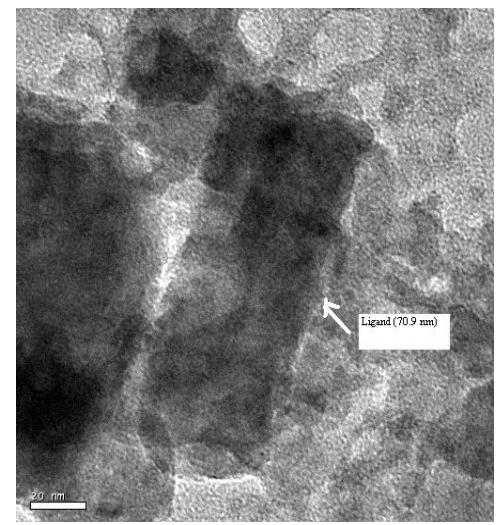

Figure 4: Ligand

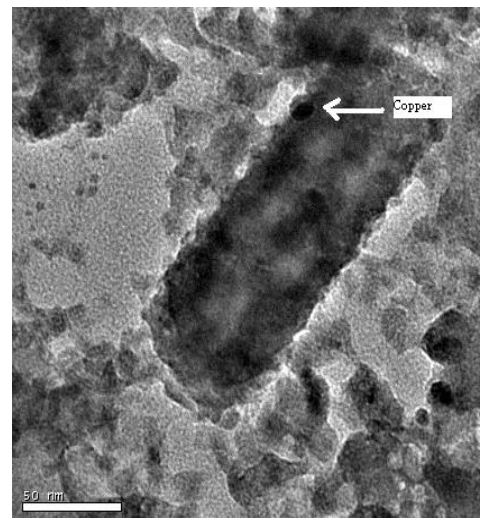

Figure 5: Presence of copper 


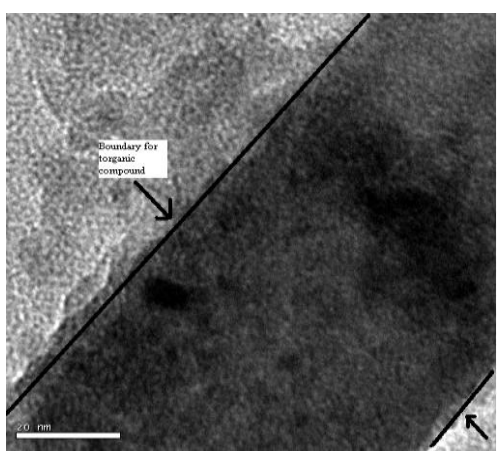

Figure 6: Boundary of ligand

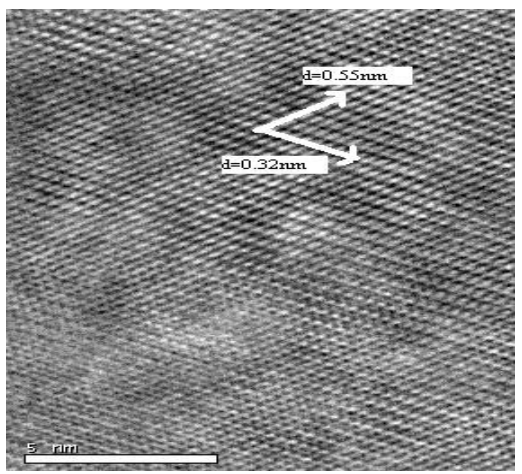

Figure 9:Periodicity

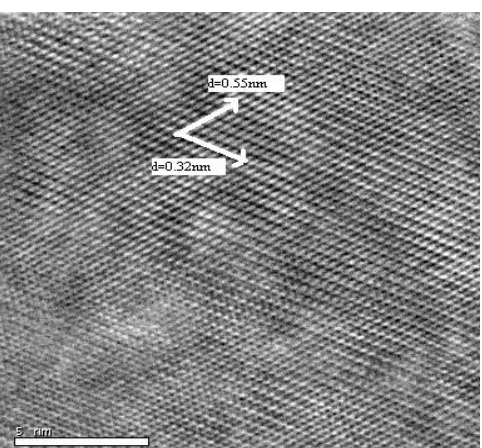

Figure 7: Planes

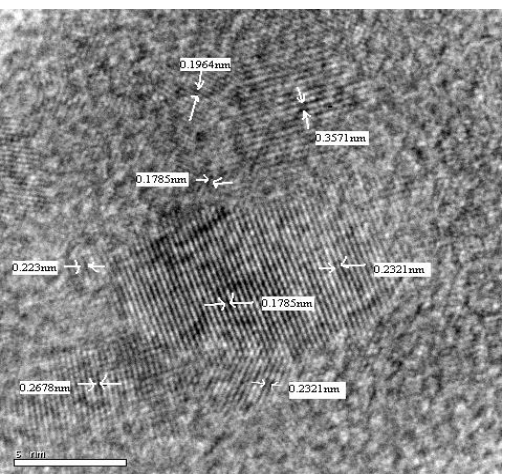

Figure 10: Particle interaction

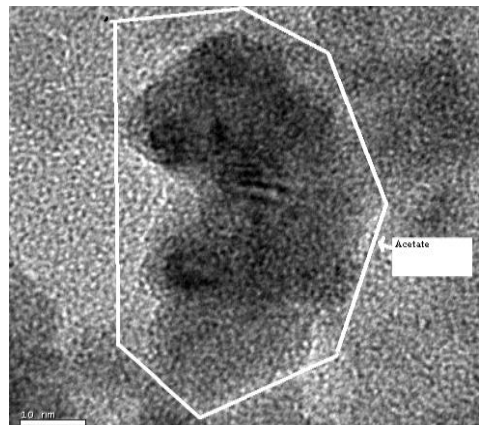

Figure 8: Presence of Acetate

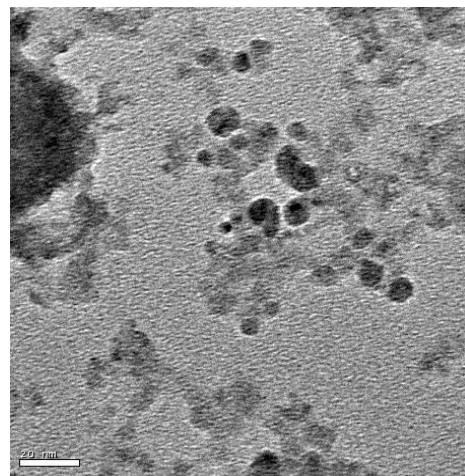

Figure 11: Particle dispersion

Table 1 : Indexing the powder XRD pattern

\begin{tabular}{lll}
\hline $2 \theta\left({ }^{\circ}\right)$ & $\mathrm{I} / \operatorname{Imax}(\%)$ & $\mathrm{d}_{\text {obs }}(\AA)$ \\
\hline 12.4 & 96.21 & 7.140 \\
13.77 & 96.68 & 6.4328 \\
16.31 & 100 & 5.4362 \\
27.84 & 82.46 & 3.2055 \\
31.95 & 88.15 & 2.8019 \\
39.42 & 49.29 & 2.2865 \\
40.56 & 46.55 & 2.2290 \\
56.65 & 38.86 & 1.6252 \\
\hline
\end{tabular}

Table 2: Diffraction peak profile

\begin{tabular}{llll}
\hline $2 \theta\left(^{\circ}\right)$ & $\left.\operatorname{FWHM}^{\circ}\right)$ & $\Delta \theta\left(^{\circ}\right)$ & $\Delta \mathrm{K}\left(\mathrm{nm}^{-1}\right)$ \\
\hline 12.4 & 0.03003 & 0.015015 & 0.0033 \\
13.77 & 0.01799 & 0.008995 & 0.0020 \\
16.31 & 0.31763 & 0.158815 & 0.035 \\
27.84 & 0.07041 & 0.035205 & 0.007 \\
31.95 & 0.2535 & 0.12675 & 0.021 \\
39.42 & 0.07464 & 0.03732 & 0.007 \\
40.56 & 0.00656 & 0.00328 & $5.64 \mathrm{E}-4$ \\
56.65 & 0.00617 & 0.003085 & $3.83 \mathrm{E}-4$ \\
\hline
\end{tabular}


Synthesis And Characterization Of Nano Structured...

Table 3: Elementary analysis

\begin{tabular}{lllll}
\hline $\begin{array}{l}\text { Element } \\
\text { (symbol) }\end{array}$ & Atomic weight & No. of atoms & & Mass present $(\%)$ \\
& & & & \\
\cline { 3 - 5 } & & & Theoretical & Experimental \\
\hline $\mathrm{C}$ & 12.01078 & 9 & 31.18 & 28.01 \\
$\mathrm{H}$ & 1.00794 & 12 & 3.49 & 2.73 \\
$\mathrm{~N}$ & 14.00674 & 2 & 8.08 & 7.01 \\
$\mathrm{O}$ & 15.99943 & 4 & 18.46 & 21.45 \\
$\mathrm{Cu}$ & 63.5463 & 1 & 18.33 & 18.64 \\
$\mathrm{Cl}$ & 35.4532 & 2 & 20.45 & 19.08 \\
\hline
\end{tabular}

The calculated Molar mass $=346.65 \mathrm{~g} / \mathrm{mol}$

Table 4 : Bond distances

\begin{tabular}{lll}
\hline S.No & Bond distances & Element \\
\hline 1 & $0.2678 \mathrm{~nm}$ & $\mathrm{H}-\mathrm{Cl}$ \\
2 & $0.223 \mathrm{~nm}$ & $\mathrm{Cu}-\mathrm{N}$ \\
3 & $0.2321 \mathrm{~nm}$ & $\mathrm{H}-\mathrm{O}$ \\
4 & $0.1785 \mathrm{~nm}$ & Pyridine N- Carboxyl O \\
5 & $0.3571 \mathrm{~nm}$ & $\mathrm{C}-\mathrm{Cl}$ \\
6 & $0.1964 \mathrm{~nm}$ & Pyridine H- Carboxyl O \\
\hline
\end{tabular}

